\title{
MRI set to win reprieve from EU ban
}

\section{Directive that limits workers' electromagnetic exposure aims for a compromise.}

A controversial piece of European Union (EU) legislation that outlaws much routine brain and body imaging in research laboratories and clinics is on course for a revamp.

The EU directive was designed to limit workers' exposure to electromagnetic fields (EMF) and was approved in 2004. But it was put on hold in 2007 after scientists and others said that it would stop them from carrying out important work without improving worker safety.

The European Commission now says that it will propose new legislation by the end of this year that addresses these issues, and will allow magnetic resonance imaging (MRI) use to be exempted from binding exposure-limit values. "We know this is only a proposal," says Stephen Keevil, a medical physicist at King's College London. "But if the final directive turns out to be like this, then everything will be fine."

The 2004 Physical Agents (EMF) Directive was originally designed to address health risks for those working in the electrical power and telecommunication industries, but it turned out to have a range of unintended consequences. Many sectors - medical, industrial and even military - claimed that the directive set occupational exposure limits that were overcautious and that would interfere with normal activities, including routine imaging, which is vital in both the clinic and the research lab. They also disputed the scientific data on which the limits had been based.

The protests earned the directive the dubious distinction of being the only piece of EU legislation ever to have been put on ice. The original directive was scheduled to be incorporated into national legislation by 30 April $2008-$ member states are normally obliged to implement EU directives within four years of their "If the final directive turns out to be like this, then everything will be fine." approval - but after the complaints this was delayed until April 2012 to allow time to consult stakeholders and, potentially, to propose revisions. The European Parliament and Council must sign up to any changes the commission proposes to make.

Even with those extra years, the timetable for repair is tight. "We hoped to have our proposal for new legislation much earlier, but it all proved complicated," admits Georges Herbillon, the commission official responsible for drafting the new rules. "Our current timetable gives 16 months for the political approval and that should be enough." But the commission is already behind schedule and, he says, much further slippage would mean that the original directive would automatically come into effect on 1 May 2012.

The directive covers the electromagnetic spectrum up to $300 \mathrm{GHz}$, the highest frequency of radio waves, but the disputes focus on the low-frequency range under $100 \mathrm{kHz}$, typically found in the vicinity of standard MRI machines. Many procedures require health or research workers to remain close to the scanner when it is running, to carry out procedures on people inside the scanner, for example. Decades of experience have produced no evidence of permanent adverse health effects, MRI scientists argue. Physical effects, such as a feeling of vertigo, or peripheral nerve stimulation resulting in a harmless twitch, may occasionally occur, but they are temporary.

The original directive banned workers from staying close to a running scanner. The

\section{US biotech firms line up for tax credits}

\section{Tucked away on page 759 of} the voluminous health-care law signed by President Barack Obama in March is a provision to aid small companies doing research and development (R\&D) in biotechnology. Starting on 21 June, many of those companies will be racing to take advantage of a tax credit worth up to $\$ 5$ million per company and totalling $\$ 1$ billion.

Called the Therapeutic

Discovery Project Program, the initiative aims to lift an industry that has struggled during the recent economic crisis. When anxious investors shifted money to low-risk investments, high-risk biopharmaceutical companies, particularly young firms with no products on the market, were left scrambling for cash (see graph).

The pressure has taken its toll.
According to the Biotechnology Industry Organization (BIO), there were at least 394 public US biotech firms in January 2008. By January 2010, 285 remained. Most of those lost were early-stage firms. "We were seeing literally a generation of biotech companies being shelved," says Alan Eisenberg, BIO's vicepresident for emerging companies and business development.

The tax credit is targeted at vulnerable young businesses only those with fewer than $\mathbf{2 5 0}$ employees are eligible - and covers up to half of the R\&D expense for qualifying projects. Because most biotech companies don't earn a profit in their early years, and therefore owe no taxes, they wouldn't benefit from a tax credit. So the programme allows those firms to convert the credits

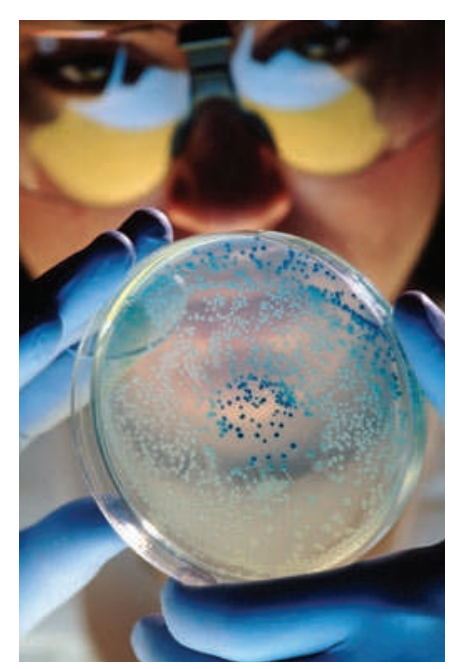

Slow growth: the US biotech industry has suffered in the recession.

into grants. In fact, the programme is largely a grants programme disguised as a tax credit, says Barry Bozeman, a professor of public policy at the University of Georgia in Athens, who notes that tax credits tend to be more politically palatable.

To be eligible, a project must demonstrate the potential to produce new therapies, reduce the cost of health care or contribute to the goal of curing cancer within 30 years. GlycoMimetics of Gaithersburg, Maryland, is one potential candidate for the credit. Rachel King, the company's chief executive, hopes the money could be used to expand clinical trials for its drug to treat sickle-cell anaemia. XOMA, a firm in Berkeley, California, will probably submit multiple applications, each for a different project, says its chief financial officer, Fred Kurland. 


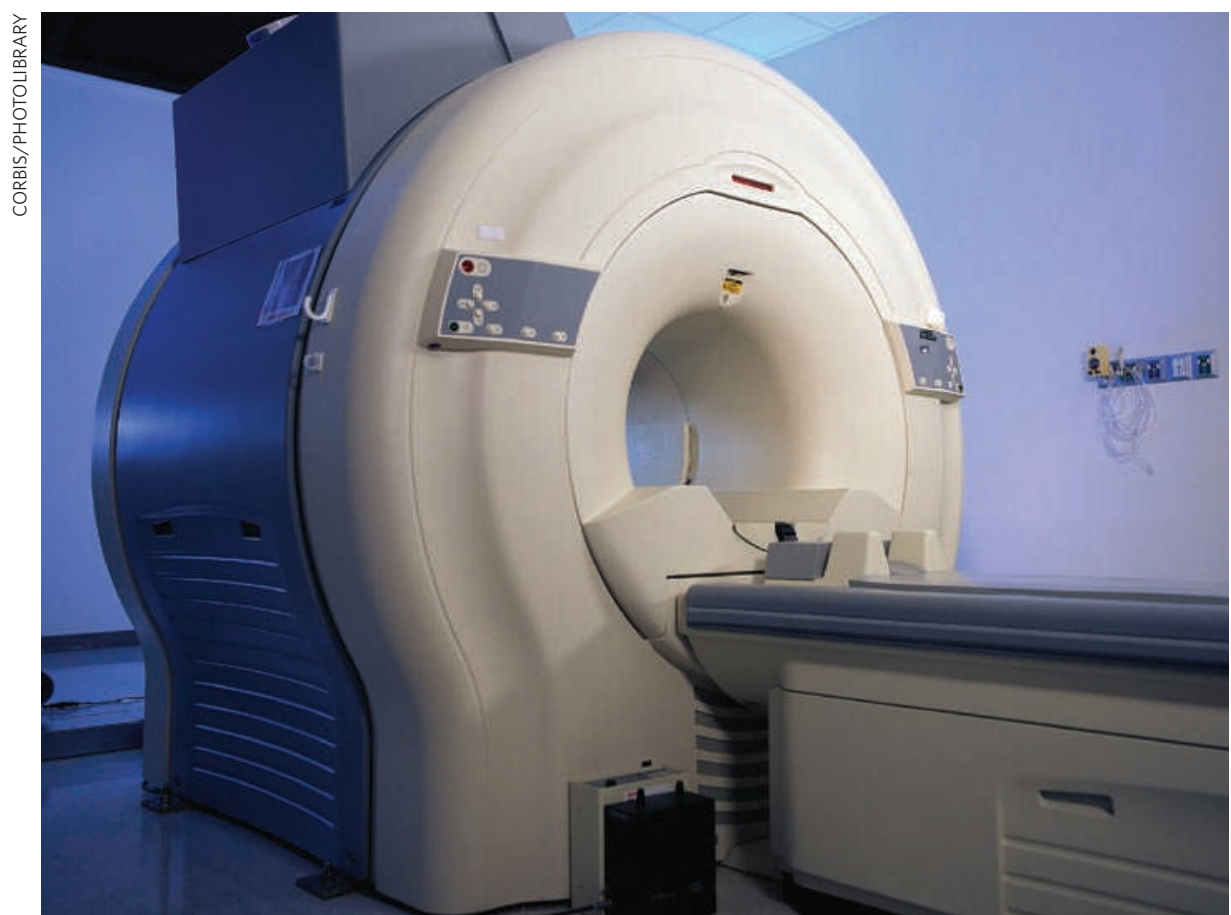

EU legislation would have stopped workers getting close to MRI scanners during operation.

calculations used to estimate safe levels of exposure were based on recommendations of the International Commission on Non-Ionizing Radiation Protection (ICNIRP), a nongovernmental organization recognized by the
World Health Organization.

But a report released this week by the European Science Foundation says that those recommendations are extrapolated from very limited experimental data with excessive

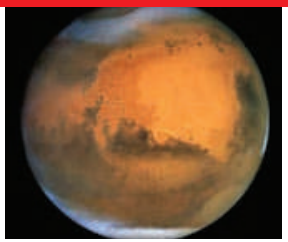

DELTAS HINT AT ANCIENT MARTIAN OCEAN

Channel mouths may have fed one body of water.

go.nature.com/7fy86X

caution. "It is nonsense - taking the precautionary principle too far," says Denis Le Bihan, director of the NeuroSpin neuroimaging project at the CEA-Saclay Centre near Paris, and a member of the expert group that prepared the report.

In its latest consultation document, the commission says that when defining adverse health and safety effects it will take the specific circumstances into account - a transient feeling of vertigo may be dangerous only if the worker is standing and at risk of falling. It also plans to consider safety calculations from agencies other than the ICNIRP, such as the international Institute of Electrical and Electronics Engineers (IEEE) and Germany's Federal Ministry of Labour and Social Affairs (BMAS), which some researchers say are more strongly grounded in science. It suggests grading the disputed sub- $100 \mathrm{kHz}$ frequency range into three categories on the basis of a risk assessment that acknowledges the higher safety limits recommended by the IEEE and BMAS, banning access only when exposure is high.

MRI would be exempt from these binding exposure limits. Instead, a Europe-wide agreement on safe working practices would be developed and workers would be given appropriate training. This, Keevil says, will avoid the problem of impeding research or medicine, but "will achieve the same aim of keeping people safe". Alison Abbott

\section{One project XOMA is likely to put forward is its lead therapeutic - an antibody that reduces inflammation.}

Syndax of Waltham, Massachusetts, a company that focuses on cancer, is still mapping out its strategy to maximize its chances of getting the credit, says its financial controller, John Pallies. "We could do one application per drug, or per type of cancer, or per patient population," he says. "There's not a good sense of how these projects are going to be evaluated."

Under the programme there is no limit to the number of projects that can be funded at a single company, and the $\$ 1$ billion total will be distributed among all qualifying projects. Eisenberg estimates that about 600 of BIO's members will apply for funds, plus about 600 companies that are not part of the organization. This deluge of applications could lead to smaller awards per proposal. "In all likelihood, with so many applications, no project is going to get more than a million dollars," says Kurland. Eisenberg points out that $85 \%$ of BIO's members with fewer than 350 employees have R\&D budgets of less than $\$ 30$ million.

The grants are clearly tiny compared with the billions often required to fully develop a new drug, but they are enough to stimulate early-stage research, says Eisenberg. "Will it mean that you don't have to go out and do other fundraising?" says Kurland. "No. But maybe it gets you over the hump, or maybe it encourages others to invest in your company."

The credit should help address concerns that US biotechnology is falling behind in the face of increasingly vigorous international competition. "The United States was the first to have a tax credit for R\&D back in 1981," says Gregory Tassey, a senior economist at the National Institute of Standards and Technology in Gaithersburg. "Since then, other countries have come up with their own. Now we're down around seventeenth in terms of actual financial impact of our R\&D credit."

For now, the credit is only mandated to cover costs incurred in 2009 and 2010, but it's a safe bet that the industry will lobby for the programme's renewal. Even so, the credit is unlikely to solve the real challenge facing the sector: how to sustain a high-risk industry that often takes a decade or longer to
BIOTECH UNDER PRESSURE Investment in US biotechnology firms took a plunge after the economic crisis in late 2008

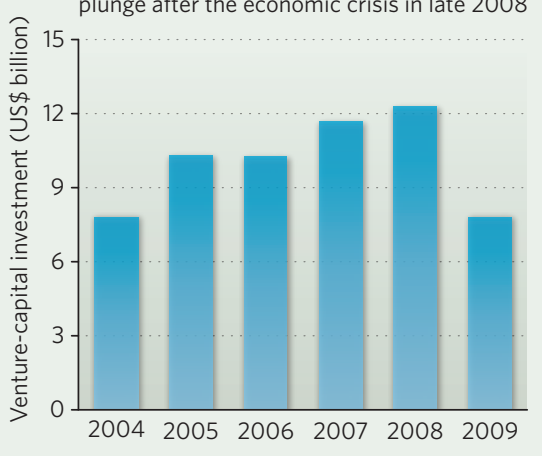

generate a viable product. "This is not going to solve any long-term problem," says William Caldwell, chief executive of Advanced Cell Technology, headquartered in Santa Monica, California. “It's just going to be part of the funds that a company can access just to stay alive." Heidi Ledford 